Nutrição e pobreza 



\title{
"Abra a felicidade"? Implicações para o vício alimentar
}

\author{
ANA LYDIA SAWATA e ANDREA FILGUEIRAS
}

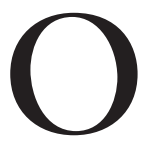
QUE É A FELICIDADE e o que pode nos trazer felicidade realmente? Aristóteles afirma que felicidade só pode ser a realização plena daquilo que é a característica singular do ser humano, aquilo que o define. E para ele a felicidade é alcançada quando o ser humano é plenamente satisfeito e realizado na sua essência que é a atividade racional e não as sensações, a nutrição ou o crescimento. Conquistar apenas a plenitude dessas últimas experiências o igualaria às plantas e aos animais, assim não poderia ser a realização plena do ser humano, mas apenas parcial. Nesse caso, pode-se falar de prazer, mas não de felicidade. Em A Ética Nicomaqueia (Reale, 2007) podemos encontrar uma descrição magistral dessa constatação:

Se dizer que a felicidade é o sumo bem parece algo sobre o qual se está de acordo, todavia sente-se a necessidade de dizer ainda algo mais preciso sobre a sua natureza. Poderemos fazer isso sem dificuldade, se examinarmos a atividade específica do ser humano. [...] E qual seria essa atividade? Não o viver, pois esse é comum também às plantas, uma vez que se busca algo que lhe seja próprio. É preciso, pois, excluir a nutrição e o crescimento. Seguiria a sensação, mas também esta se mostra comum ao cavalo, ao boi e a todo animal. Resta, pois, uma vida ativa própria do ser racional. [...], e esta é constituída pela atividade da alma e das ações racionais. [...] Se, pois, é assim, então o bem próprio do ser humano é a atividade da alma segundo a virtude, e se múltiplas são as virtudes, segundo a melhor e a mais perfeita. E isso vale também para uma vida realizada. Com efeito, uma única andorinha ou um único dia não fazem verão; assim também um único dia ou um breve momento não proporcionam a beatitude ou a felicidade. (Aristóteles, A Ética Nicomaqueia, A 7, 1097 b 22-1098 a 20)

É claro, portanto, que um momento de prazer não pode ser considerado felicidade. Para os filósofos gregos, prazer (hedonia) e felicidade (eudaimonia) não são sinônimos. Platão e Aristóteles afirmam em muitas passagens que confundi-los traz grandes males aos seres humanos.

Eudaimonia significa para os gregos ter um daimon (espírito) bom e protetor que leva, consequentemente, a uma vida próspera (Reale, 2009). O filosofo pré-socrático Heráclito já afirmava que a eudaimonia não está nas coisas corpóreas: "Se a felicidade consistisse nos prazeres do corpo, deveríamos dizer que são felizes os bois, quando comem”.

Uma passagem de Platão em Górgias diz explicitamente que a felicidade se alcança a partir da educação da alma ou espírito para buscar a justiça, o bem, o belo e o verdadeiro, e assim a virtude: 
Polo - Evidentemente, ó Sócrates, dirás que nem mesmo o grande Rei é feliz. Sócrates - E direi simplesmente a verdade, pois não sei como ele se encontra quanto à formação interior e quanto à justiça.

Polo - Mas como? Toda a felicidade consiste nisso?

Sócrates - A meu ver sim, ó Polo. Com efeito, eu digo que quem é honesto e bom, seja homem ou mulher, é feliz, e que o injusto e mau é infeliz. (Platão, Górgias, 470 e)

Aristóteles explicita ulteriormente que a virtude se alcança quando aprendemos a viver a “justa medida” com relação aos nossos sentimentos, paixões e ações:

Com relação ao temor, ao ardor, ao desejo, a ira, a piedade, e em geral, ao gozo e a dor há um excesso e uma falta, e ambos não são bons; mas se experimentamos aquelas paixões quando se deve, no que se deve, contra quem se deve, com a finalidade e do modo que se deve, então estaremos no meio e na excelência, que são próprios da virtude. [...] A virtude é uma certa mediania, quem tem por finalidade a justa medida. (Aristóteles, A Ética Nicomaqueia, B 6, 1106 b 18-28)

Assim, a "justa medida” é um ato da razão que impõe a sentimentos, ações ou atitudes um controle, sem o qual esses tenderiam ao desequilíbrio por falta ou excesso de algo. E o desequilíbrio leva à infelicidade. Esclarece-se assim que ambas as circunstâncias, falta de gozo ou excesso desse, geram perda da felicidade.

Ilustrativas nesse aspecto são pesquisas recentes que relacionam salário e satisfação com a vida onde o pico de satisfação encontra-se no meio termo, e indivíduos muito ricos ou muito pobres têm escores de satisfação mais baixos (Kringelbach; Berridge, 2009).

O mundo se alimenta cada vez pior. Desde a década de 1980 com o grande crescimento dos alimentos industrializados (McCrory et al., 1999) e do crescimento do hábito de comer fora de casa houve um crescimento do número de pessoas de todos os extratos sociais que sofrem de distúrbios alimentares e com as doenças crônicas relacionadas a esses como obesidade, diabetes e doenças cardiovasculares. Quase dois bilhões de pessoas têm atualmente excesso de peso (IBGE, 2010). O problema alimentar vem crescendo continuamente e recentemente a obesidade passou a ser uma doença que acomete cada vez maior número de crianças e adolescentes. Embora a obesidade seja uma doença multicausal, existem fortes evidências da influência da propaganda e do ambiente obesogênico na mudança dos hábitos alimentares.

Como isso foi possível? A alimentação de um povo sempre foi uma das características mais específicas de cada cultura desde tempos primordiais. Apesar disso as indústrias e o comércio de alimentos desenvolveram técnicas para venda e para indução de hábitos alimentares novos que foram capazes de ultrapassar a profunda influência cultural de cada povo ao se alimentar. E mais recentemente, foram capazes de desenvolver sabores, imagens e técnicas de persuasão para atingir as crianças de todas as classes sociais e mudar seus hábitos e de suas famílias. 
Não é difícil a esse ponto perceber que tocaram em algo muito profundo no ser humano, naquilo que mais o define e o faz mover-se: a busca da felicidade.

Este artigo tem como objetivo debruçar-se sobre pesquisas recentes da influência do consumo de alimentos palatáveis na neuroanatomia funcional do prazer e sua implicação para o vício alimentar. E, por fim, discutir brevemente o Modelo Transteórico como ferramenta para intervenção no tratamento da obesidade.

\section{Neuroanatomia funcional do prazer}

Estudos sobre a neuroanatomia do prazer revelam a existência de centros cerebrais que trabalham em rede ativando neurotransmissores que controlam os eventos e estados de prazer, e que compõem o chamado circuito cerebral hedônico (Kringelbach; Berridge, 2009). Esses centros controlam três comportamentos distintos embora interligados: gostar, quever e aprender, e cada um deles controla respostas neurais conscientes e inconscientes. Sabemos que o prazer cresce quando à experiência de prazer se acrescenta a lembrança do prazer obtido pela mesma circunstância no passado. Vários desses centros estão na região mais central do sistema nervoso onde se localiza o sistema límbico, mas possuem conexões neurais muito extensas com as regiões do córtex cerebral onde estão localizadas as funções conscientes e de ordem superior como os prazeres musicais, artísticos e transcendentes (Figura 1).

\section{“Gostar"}

A região mais estudada até o momento é o núcleo acumbens (Figura 1) onde se localiza primordialmente o controle da sensação de "gostar" e que não tem mais de um centímetro cúbico de extensão no cérebro humano. Experimentos em animais mostraram aumento de duas/três vezes na sensação de "gostar" quando neurônios dessa região foram estimulados por microinjeções de substâncias doces e moduladores neuroquímicos como os hormônios opioides e endocanabinoides. Esses hormônios são produzidos nas células nervosas do nosso organismo e têm efeito semelhante ao das drogas como ópio ou Cannabis (maconha) daí o seu nome. São nossos estimuladores endógenos de prazer e são produzidos para direcionar nossa atenção específica para as atividades fundamentais para a sobrevivência como buscar e comer alimentos ricos em energia e nutrientes (açúcar, carnes, sal), atrair-nos para a reprodução e cuidado da prole etc.

\section{"Quever"}

O prazer traduz-se também em processos neurais que ativam comportamentos de "querer", busca insistente, procura e atenção focalizada que podem durar dias (Sawaya, 2013a; 2013b). O objeto do nosso desejo torna-se um estimulo saliente que predomina sobre outros estímulos. Aquela “ideia” que não se consegue tirar da cabeça e que vem como pensamento involuntário. Esse comportamento depende principalmente da ativação do neuro-hormônio dopamina no sistema límbico. O comportamento de "gostar" é diferente e independente daquele de “querer” (Berridge, 2007). É possível “querer” sem “gostar” e esse 


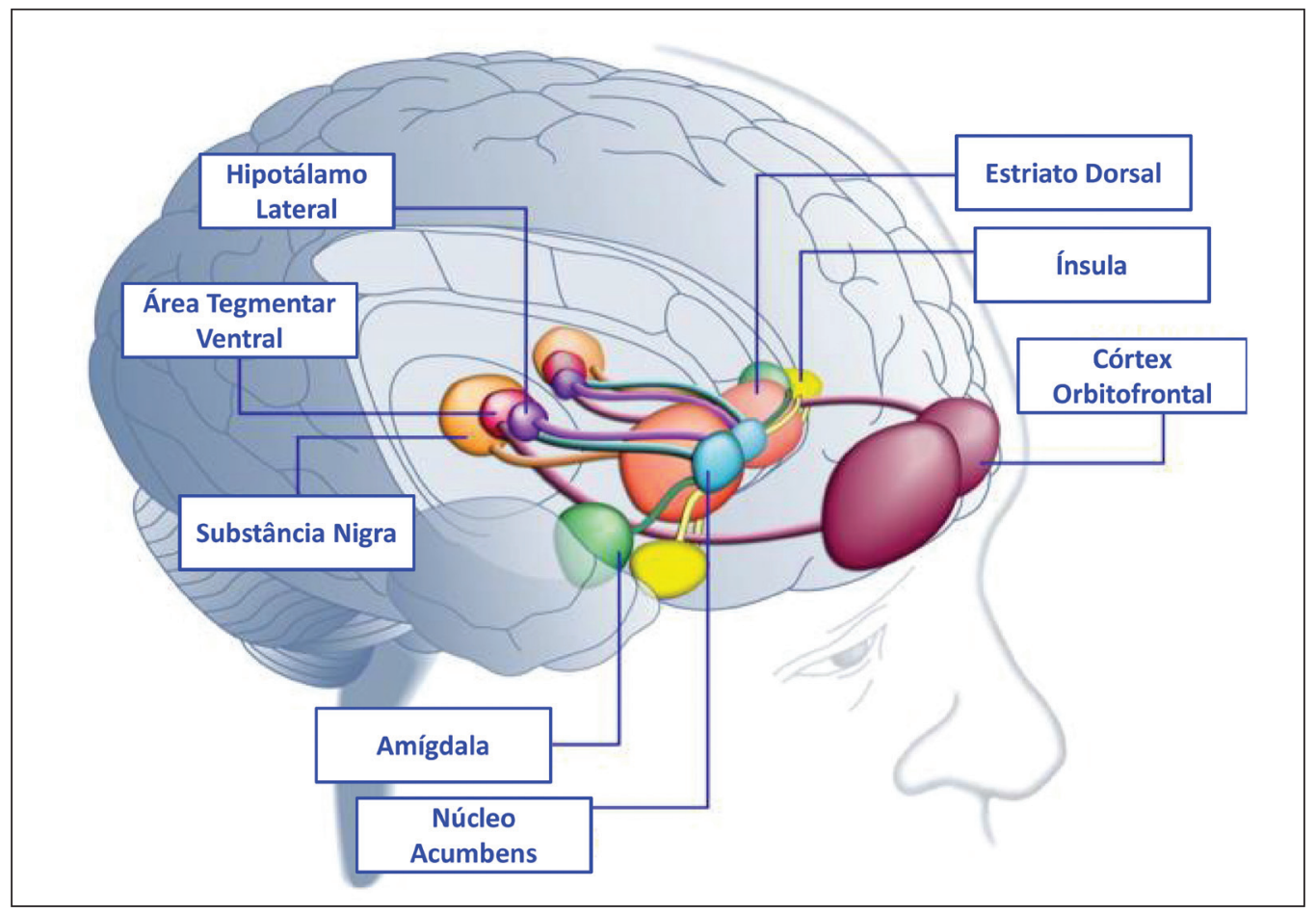

Figura 1 - Áreas do sistema nervoso central que são estimuladas pela ingestão de alimentos palatáveis ou pela presença de sinais visuais, auditivos, gustativos e ambientais que ativam a memória e a procura desses alimentos. O córtex orbitofrontal e a amígdala são importantes para a codificação e resposta consciente a alimentos recompensadores. A ínsula processa informação relacionada ao sabor dos alimentos e sua avaliação hedônica. $\mathrm{O}$ núcleo acumbens e o estriato dorsal que recebem informações do sistema dopaminérgico (de células nervosas produtoras do neurotransmissor dopamina) da área tegmentar ventral e substância nigra regulam as propriedades motivacionais e os estímulos salientes (atenção dominante). Atribui-se ao hipotálamo lateral a regulação da procura específica por um alimento palatável e a geração de respostas recompensadoras. Essas áreas cerebrais trabalham em rede de forma a regular o comportamento de aprendizagem das propriedades hedônicas de um alimento, direcionam a atenção para a obtenção desse e os esforços para obtê-lo levando a sensações prazerosas e de recompensa após sua ingestão. Controlam os mecanismos de saciedade e favorecem a ingestão oportunista ( sempre que o alimento ou um sinal desse estiver disponível, mesmo na ausência de fome) (modificado de Kenny, 2011).

é exatamente o caso do comportamento de vício. O descontrole irracional do comportamento de "querer" está associado a uma diminuição da resposta à estimulação dopaminérgica no sistema límbico e outros centros associados. Por esse motivo o indivíduo necessita de substâncias ou eventos estimulantes (ganhar dinheiro, droga, sexo, alimentos com sabor doce, entre outros) em maior quantidade e frequência para obter a mesma sensação de prazer que um indivíduo não viciado. Essa dissociação é possível, pois os centros que controlam o comporta- 
mento de "querer" estão localizados principalmente no sistema límbico e separados dos sistemas que geram a consciência do prazer que estão principalmente nas regiões do córtex cerebral como o córtex orbitofrontal (Figura 1). Essa é a razão do porquê pessoas viciadas apresentam comportamento compulsivo de "querer" e fazer todo o esforço possível para obter drogas, por exemplo, e, ao mesmo tempo, do ponto de vista da consciência, não desejem que seja assim. Essa é certamente uma receita para grande infelicidade (Kringelbach; Berridge, 2009). Esse fenômeno ocorre pelo uso abusivo de uma determinada substância ou repetição excessiva de um determinado comportamento e parece gerar uma "resistência" da resposta excitatória nos centros nervosos, diminuindo como mecanismo de defesa sua "sensibilidade" a estímulos.

\section{"Aprender"}

Um terceiro componente que influencia grandemente a experiência de prazer é o "aprendizado". Em uma extensa revisão (Sawaya, 2013a) mostramos que alimentos e bebidas industrializados/comercializados altamente palatáveis, ou seja, produzidos para gerar grande prazer promovem alterações neuroanatômicas que podem ser permanentes e passar para os filhos e próximas gerações. Essas alterações causam um desbalanço fisiológico que inclui modificações em processos neurais e metabólicos envolvendo processos de memória, aprendizagem e influências do contexto social. Sabe-se que cada vez que trazemos à consciência uma lembrança, acabamos por conservá-la melhor em nossa memória, ou seja, com muito mais facilidade e "naturalmente" vem à nossa mente. Isso funciona tanto para lembranças positivas como para negativas. Cada vez que lembramos um fato, uma situação, a memória desse fato é reforçada em nossa mente. Ao contrário, se não nos lembramos de algo por muito tempo, a memória desse fato vai aos poucos sendo perdida. Os mecanismos associados ao processo de memória envolvem duas etapas: a informação é trazida à nossa consciência e, em seguida, uma vez que foi trazida à consciência, é recopiada em nossa memória. Essa "nova" memória apaga as memórias anteriores, renovando sempre as informações contidas nela.

\section{Reflexo condicionado}

Cada vez que a lembrança de um fato é reescrita em nossa memória, ele pode ser reescrito de forma ligeiramente diferente. Esse procedimento tem sido utilizado para extinguir a memória recorrente da ânsia por drogas e recaídas. Sabe-se que o uso das drogas e as recaídas envolvem associações mnemônicas entre o ato de consumir a droga, os ambientes propícios onde esse consumo se dá e os efeitos da estimulação das drogas nos centros cerebrais que controlam o "querer" e o "prazer". Essas associações são aprendidas e guardadas na memória, e geram também reflexos condicionados.

Experimentos têm sido desenvolvidos para apagar os condicionamentos e sinais ambientais que são capazes de persistir mesmo após longo período de abstinência. Mudar de ambiente rapidamente (10 minutos após o consumo da 
droga) faz que ratos "esqueçam" a associação entre droga e ambiente e passem a não mais procurar o ambiente onde normalmente encontravam a droga (Xue et al., 2012). Quando o experimento foi realizado com pessoas dependentes de heroína, a mudança de ambiente após 10 minutos (mas não uma hora depois) permitiu que a memória ligada à droga fosse reescrita e eles não experimentaram mais a ânsia pela droga como antes. Esse fato mostra a potência do ambiente e contexto social na neuroanatomia do prazer.

\section{Propagandas de alimentos e bebidas}

Crescem também evidências de que as propagandas de alimentos e bebidas açucaradas ou com sabor doce (refrigerantes, sucos de frutas industriais, sucos em pó) geram esse mesmo reflexo condicionado: vejo - lembro - quero ansiosamente - me sinto recompensado momentaneamente (Sawaya, 2013a). E esses estímulos têm aumentado o comer/beber como vício, especialmente nas pessoas mais suscetíveis. Nesse sentido, são particularmente perigosas e nocivas à saúde mensagens que chegam frequentemente à consciência e são, portanto, com frequência reescritas na memória gerando reflexos condicionados, como a propaganda de refrigerante que intitula este artigo. Há muitos exemplos, pois essa técnica mnemônica e de indução de comportamento tem sido amplamente usada pela indústria, eis alguns: "amo muito tudo isso", "um sabor inesquecível", "exageradamente gostoso", "com sabor de quero mais", "impossível comer um só". De todas as faixas etárias, as crianças são as mais suscetíveis à criação desses reflexos condicionados e também o principal agente para indução do consumo de alimentos e bebidas industrializados na família.

Hoje não há mais dúvidas sobre a influência das propagandas, sobretudo na televisão e nas escolas para o aumento excessivo do consumo de alimentos/ bebidas industrializados e comercializados. Estamos vivenciando um nova geração de crianças e adolescentes com excesso de peso que veem muitas horas de televisão (há relação direta entre horas assistindo televisão e ganho de peso), chamada por alguns autores de obesiTV (Boulos et al., 2012).

Um exemplo da força do aprendizado na aquisição de um hábito e na geração do prazer, reforçado pelo ambiente e contexto social, é o consumo crescente de cerveja no Brasil. A cerveja nasceu em países europeus onde a baixa temperatura impedia a produção de uva e vinho. Além de aumentar a temperatura corporal, é diurética, desidrata e, portanto, aumenta a sede. Foi, justamente, desenvolvida em climas frios após a descoberta da sua capacidade de aquecer o corpo e fornecer energia. Mas uma estratégia de marketing extremamente bem-sucedida da indústria de bebidas conseguiu mudar o hábito de beber cachaça e introduzir a cerveja através da invenção da cerveja "estupidamente" gelada; o que nos países de origem dessa seria inaceitável. Assim, passou a vender a sensação refrescante, o copo gelado, juntamente à cerveja. A maciça propaganda com mulheres e lugares bonitos, jovens em férias, direcionada ao público masculino e mais recentemente ao jovem e feminino impôs um contexto social que tornou a 
cerveja um ícone para se encontrar com os amigos e a bebida das férias de verão em nossas praias tropicais. Mas, poderíamos nos perguntar, os sinais metabólicos internos do aumento desagradável da temperatura corporal, assim como da sede não são percebidos e levados à consciência? Sim, mas o contexto social e o aprendizado durante a juventude, as ocasiões agradáveis em que é consumida tornaram-se o estimulo predominante ou saliente para seu consumo obliterando os sinais metabólicos.

Esse exemplo nos introduz a um último aspecto da neuroanatomia funcional do prazer, ou seja, a experiência humana de "gostar", "querer" e "aprender" implica a tomada de consciência desses fenômenos e, portanto, o envolvimento do córtex cerebral onde nossas funções mais complexas são codificadas. De fato, regiões corticais como o córtex orbitofrontal e a ínsula fazem parte do circuito cerebral hedônico (Figura 1). Estudos em seres humanos que se utilizam de técnicas de neuroimagens mostraram que essas regiões são ativadas quando imagens, sons, aromas, ou a presença num determinado ambiente antecipam o prazer, evocam a memória de experiências prazerosas e envolvem decisões de buscar de novo a experiência (Kringelbach; Rolls, 2004).

\section{Alimentos e bebidas recompensadores}

A indústria de alimentos e bebidas e o comércio de alimentos consumidos fora de casa em restaurantes, cantinas e lanchonetes desenvolveram uma série de produtos que ativam sobremaneira o sistema hedônico, geram consumo excessivo na ausência de fome e descontrole alimentar. Emoções e sentimentos prazerosos são respostas mentais que servem para reforçar os benefícios ou evitar os efeitos nocivos de estímulos ambientais e comportamentais. Os três componentes da dieta moderna que respondem a essas características são: açúcar, gordura e sal; e a mistura deles em doses "certas" tem efeito somatório na geração de prazer (Sawaya, 2013b). Alimentos ricos em açúcar, gordura e sal geram mais do que outros alimentos emoções positivas que aumentam a motivação para obtê-los, tão logo sejam lembrados ou estejam disponíveis ao alcance da mão, ou seja, ingeri-los é recompensador. Nosso organismo desenvolveu um apetite particular por eles, pois garantem maior disponibilidade de energia como o açúcar e a gordura, enquanto o sal garante o balanço hidroeletrolítico vital para o funcionamento do organismo.

Esses componentes, quando combinados e acrescentados em maior quantidade à comida, direcionam o consumidor a comer na ausência de fome, não enjoar e lembrar-se com mais facilidade da sensação prazerosa a ponto de escolher e preferir aquele produto entre outros (Sawaya, 2013b). Foram três as estratégias principais para se obter esse resultado (Kessler, 2009): a) a criação de uma percepção positiva sobre um produto, encorajando-nos a ir atrás dele; b) a informação de que teremos uma experiência prazerosa e recompensadora ao adquirir aquele produto, até chegar a dizer que ingeri-lo nos fará "felizes"; c) exposição frequente da marca, da embalagem do produto, da foto do restaurante, 
de forma a gerar uma aprendizagem dos sinais relacionados ao produto fazendo que esse venha à memória inesperada e repentinamente, quando passamos numa determinada rua, quando saímos da escola, quando vamos ao supermercado ou vemos um outdoor. Assim, quando temos diante dos olhos alguns bombons, biscoitos, salgadinhos ou batata frita, e sentimos o aroma deles, é praticamente impossível não apanhar um. E, logo depois, esse gesto "abre o apetite", e nos faz querer mais. Naquele momento podemos não estar com fome e pode ser que nem tenhamos o hábito de ingeri-los, mas a "sua presença" focaliza a nossa atenção até que respondamos ao estímulo que eles suscitaram. Eles se tornaram um estímulo saliente, com capacidade de capturar predominantemente a nossa atenção.

\section{Controle hormonal}

Alimentos ricos nesses ingredientes podem manter o seu efeito estimulante por um longo período através da liberação mais prolongada de dopamina pelo sistema hedônico. Estudos em animais mostraram que a liberação desse neurotransmissor não sofre o processo de habituação quando alimentos altamente palatáveis são ingeridos em relação àqueles menos palatáveis como a ração normal (Norgren et al., 2006). Esse fenômeno mostra que o organismo vê vantagens na ingestão desses alimentos em relação a outros, e inibe o processo de habituação, favorecendo o consumo sempre que há oportunidade. A liberação de dopamina é maior se o alimento palatável é oferecido em pequenas quantidades de forma intermitente, se o animal pode antecipar sua oferta por algum sinal ambiental reconhecível, ou ainda se o horário é mantido a cada dia. O grau de palatabilidade de um alimento é calculado pela intensidade da percepção hedônica dos sinais orossensoriais (aroma, sabor, imagem, textura) provocados por este (Yeomans, 1998).

Alimentos palatáveis também retardam a liberação do neurotransmissor acetilcolina que controla a atividade nervosa do sistema parassimpático no trato gastrintestinal ativando a digestão e absorção de alimentos (Rada et al., 2005). O pico de acetilcolina ocorre no final de uma refeição e seu retardo aumenta a quantidade de alimentos ingeridos. Os hormônios leptina (produzida no tecido adiposo) e a insulina (produzida no pâncreas) também atuam diretamente nos neurônios dopaminérgicos modulando o "querer" um alimento (Zheng et al., 2009). Em indivíduos magros, a leptina sinaliza ao cérebro o tamanho do tecido adiposo e diminui o apetite e a ingestão alimentar sempre que o tamanho desse exceder o peso normal; mas inúmeros estudos revelaram que o organismo obeso desenvolve resistência cerebral a esse hormônio prejudicando essa capacidade (Kenny, 2011). A atividade neural no núcleo acumbens excitada por estímulos visuais é muito alta em adolescentes hiperfágicos com deficiência de leptina. A administração desse hormônio normaliza a excitação neural ao mesmo tempo que esses indivíduos relatam atenuação da sensação de "prazer" pela ingestão do alimento. Infusões de leptina nessas áreas nervosas inibem as atividades dos 
neurônios dopaminérgicos e diminuem a ingestão alimentar em ratos. A inibição dopaminérgica aumenta a ingestão alimentar, a atividade motora (ir à busca do alimento) e a preferência por comida palatável. Ainda, hormônios gastrointestinais como a grelina que, ao contrário da leptina, aumenta a sensação de fome e $P \Upsilon$ que suprime a ingestão alimentar, tem efeitos diretos nos centros de controle de prazer. Sinteticamente, poderíamos dizer que os alimentos palatáveis alteram os hormônios reguladores do apetite com atuação direta nos centros hedônicos.

\section{Alterações anatômicas e genéticas no sistema nervoso}

A ingestão frequente e em excesso de alimentos palatáveis e bebidas com sabor doce gera modificações não apenas funcionais, mas ainda mais profundas, pois há evidências crescentes de modificação na plasticidade neural (formação e produção das células nervosas) e na expressão gênica (que controlam a atividade celular). A ingestão de açúcar durante semanas tem a capacidade de modificar a expressão gênica e rearranjar os circuitos nervosos de recompensa e prazer (Spangler et al., 2004). Observou-se em obesos uma deficiência na atividade celular da dopamina. Ainda, estudos em camundongos alimentados durante o período de crescimento com dietas ricas em gorduras mostraram alteração na expressão dos genes de um grande número de neuro-hormônios que atuam no hipotálamo e que controlam o apetite e a ingestão alimentar (NPY, orexina, galanina, entre outros) e consequentemente nos respectivos circuitos neurais (Ferretti et al., 2011). Essas modificações ocorridas no início da vida na atividade gênica e na produção desses hormônios estavam associadas ao desenvolvimento da obesidade na vida adulta.

Alimentos palatáveis ricos em nutrientes recompensadores como açúcar, gordura e sal alteram, portanto, não só o funcionamento do sistema nervoso central e o controle hormonal do trato gastrointestinal, mas também modificam o código genético ao determinar o ganho de peso ao longo de todo o ciclo de vida.

\section{Consumo excessivo}

\section{Açúcar}

A Organização Mundial da Saúde (WHO, 2003) estabeleceu o limite de até $10 \%$ da ingestão energética total para o consumo de açúcar e o mesmo critério foi adotado pelo Ministério da Saúde brasileiro (Brasil, 2006). Um estudo recente em adolescentes paulistas de classe media (Colucci et al., 2012) mostrou que o consumo de açúcar estava acima do recomendado (12\%) para meninos e meninas. Os refrigerantes eram a principal fonte de açúcar na dieta (34\% para os meninos e $32 \%$ para as meninas), seguido pelo açúcar de adição (colocado à mesa) e achocolatados (11\%). Outro estudo (Feferbaum et al., 2012) realizado em cinco cidades brasileiras (São Paulo, Belo Horizonte, Porto Alegre, Rio de Janeiro e Recife) em meninos e meninas de diferentes níveis socioeconômicos apresentou resultados ainda piores: $37 \%$ e $45 \%$ do total de energia ingerida em 
forma de líquidos por crianças de 3-6 anos e 7-10 anos respectivamente provinham de bebidas açucaradas. O consumo de refrigerantes aumentou em $20 \%$ dos 3 aos 17 anos de idade.

Muitos estudos evidenciaram que o consumo de açúcar é um dos principais responsáveis pelo ganho de peso excessivo de crianças e adolescentes e pelo aumento futuro no aparecimento de diabetes e doenças cardiovasculares (Johnson et al., 2007; Brown et al., 2008; Barquera et al., 2010). A associação entre consumo de bebidas açucaradas e doenças futuras decorre do fato que o açúcar quando ingerido em forma líquida é rapidamente absorvido, por isso aumenta a fome em curto prazo, hiperestimula a produção de insulina pelo pâncreas (sobrecarregando o funcionamento pancreático e aumentando o risco de falência desse órgão e a diabetes) e promove a produção de gordura pelo fígado (Malik et al., 2010). A Pesquisa de Orçamentos Familiares (POF) de 2008-2009 mostrou que o sobrepeso em meninos ( 10 a 19 anos) aumentou de $3,7 \%$ (1974$1975)$ para $21,7 \%(2008-2009)$ e em meninas, de $7,6 \%$ para $19,4 \%$ no mesmo período (IBGE, 2010).

\section{Sal}

O sal adicionado durante o processamento industrial é responsável por mais de três quartos do sal ingerido (Karppanen; Marvaala, 2006). O tamanho da porção de alimentos comercializados vem crescendo continuamente e não há evidências de diminuição da quantidade de sal. A ingestão de sal aumentou também com a introdução de lanches industrializados salgados e o hábito crescente de ingerir refeições fora do domicilio, especialmente em restaurantes que servem refeições rápidas.

A sede e a ingestão de água são respostas fisiológicas inevitáveis à ingestão elevada de sal (Tey et al., 2012). O sal tem papel determinante no controle do balanço hidroeletrolítico, função renal e pressão arterial. Um aumento na ingestão de sal é sempre acompanhado por aumento na ingestão de líquidos e na pressão arterial. Assim, a ingestão elevada de sal é um dos fatores responsáveis pelo aumento do consumo de refrigerantes e bebidas açucaradas; e muitas indústrias se beneficiam dessa crescente ingestão de água dependente do sal. Nos Estados Unidos, por exemplo, o consumo per capita de refrigerantes em 2004 era de aproximadamente 198 litros, enquanto em 1983, com uma ingestão de sal 30\% menor, o consumo de refrigerantes era também $24 \%$ menor (Tey et al., 2012).

Sabe-se que o sal tem um efeito neuroendócrino semelhante ao descrito no vício por drogas e, portanto, é hoje considerado como uma substância que pode causar dependência (Cocores; Gold, 2009). Esse efeito parece ocorrer através da estimulação pelo sal do sistema de prazer via receptores opioides e dopaminérgicos cerebrais. A ativação do sistema límbico opioide está envolvida no aumento da ingestão de sódio em indivíduos que sofreram redução no consumo de alimentos salgados e falta de sal, independentemente do estado saciado. Exposição no início da vida a altas concentrações de sódio, quer pelo leite materno, quer 
por fórmulas industriais para bebês, determina a quantidade de sal ingerido no futuro. Crianças que foram habituadas a certos alimentos salgados sofrem na sua ausência e têm comportamento de procura e determinação focalizada por sua obtenção, semelhante ao comportamento relacionado ao consumo de drogas.

\section{Gordura}

A gordura tem sido consumida em quantidade crescente no mundo moderno. Em animais, a ingestão de gordura ativa os centros hedônicos e núcleo acumbens e aumenta a liberação de dopamina (Manabe et al., 2010). Esses efeitos incluem modificações na expressão gênica, na formação das células nervosas e atividade do sistema nervoso ao longo de todo o ciclo de vida. Além das alterações na ação e controle dopaminérgico, ocorrem também alterações nos neurotransmissores opioides. Naloxone, uma droga que inibe os receptores opioides, reduz a preferência por dietas ricas em gordura em seres humanos.

\section{Vício alimentar}

Sabemos que certos indivíduos podem desenvolver padrões de comportamento descontrolados ao consumir substâncias que causam prazer (Sawaya, 2013a; Blumenthal; Gold, 2010). O vício é definido como uma doença crônica com recaídas que está no final de um processo de padrões de comportamento desadaptados (Blumenthal; Gold, 2010). Embora alguns indivíduos nunca avancem além da experimentação, outros atravessam com maior ou menor facilidade um período de consumo regular, abuso e dependência. A progressão patológica desse comportamento é caracterizada por: atenção focalizada para o objeto, aumento do consumo ou frequência da atividade, tolerância, negação ou gestos para encobrir o uso ou a atividade, seguidos pelas de consequências médicas, psicológicas e sociais relacionadas diretamente à continuidade do comportamento, e por fim, por uma "atração fatal" pela substância ou atividade por parte do paciente.

O vício progride através de três estágios distintos, cada um definido por um sintoma ou sinal: o primeiro estágio é caracterizado pela compulsão episódica para o consumo ou procura pela atividade; no segundo estágio o indivíduo apresenta sintomas de desejo intenso e sente falta do objeto ou atividade; e no terceiro estágio experimenta sintomas de abstinência (ibidem). Todos esses sintomas e sinais são fortemente afetados pela presença de estresse. É bem conhecido que o vício por drogas resulta da usurpação das vias neurológicas que estão envolvidas e regulam os sistemas de recompensa, motivação, tomada de decisão, aprendizado e memória. As drogas "sequestram" esses sistemas neurais, impedindo o balanço fisiológico normal e forçando-os a tornar-se hiper-responsivos àquelas substâncias em particular. $\mathrm{O}$ comportamento de ânsia pela droga não é motivado apenas pelos efeitos "prazerosos" da droga, mas também, pelo estado negativo e de mal-estar causado pela sua abstinência.

Vários circuitos neurais estão envolvidos nesse controle, assim como vários hormônios: dopamina, acetilcolina, opioides, e serotonina (responsável pela es- 

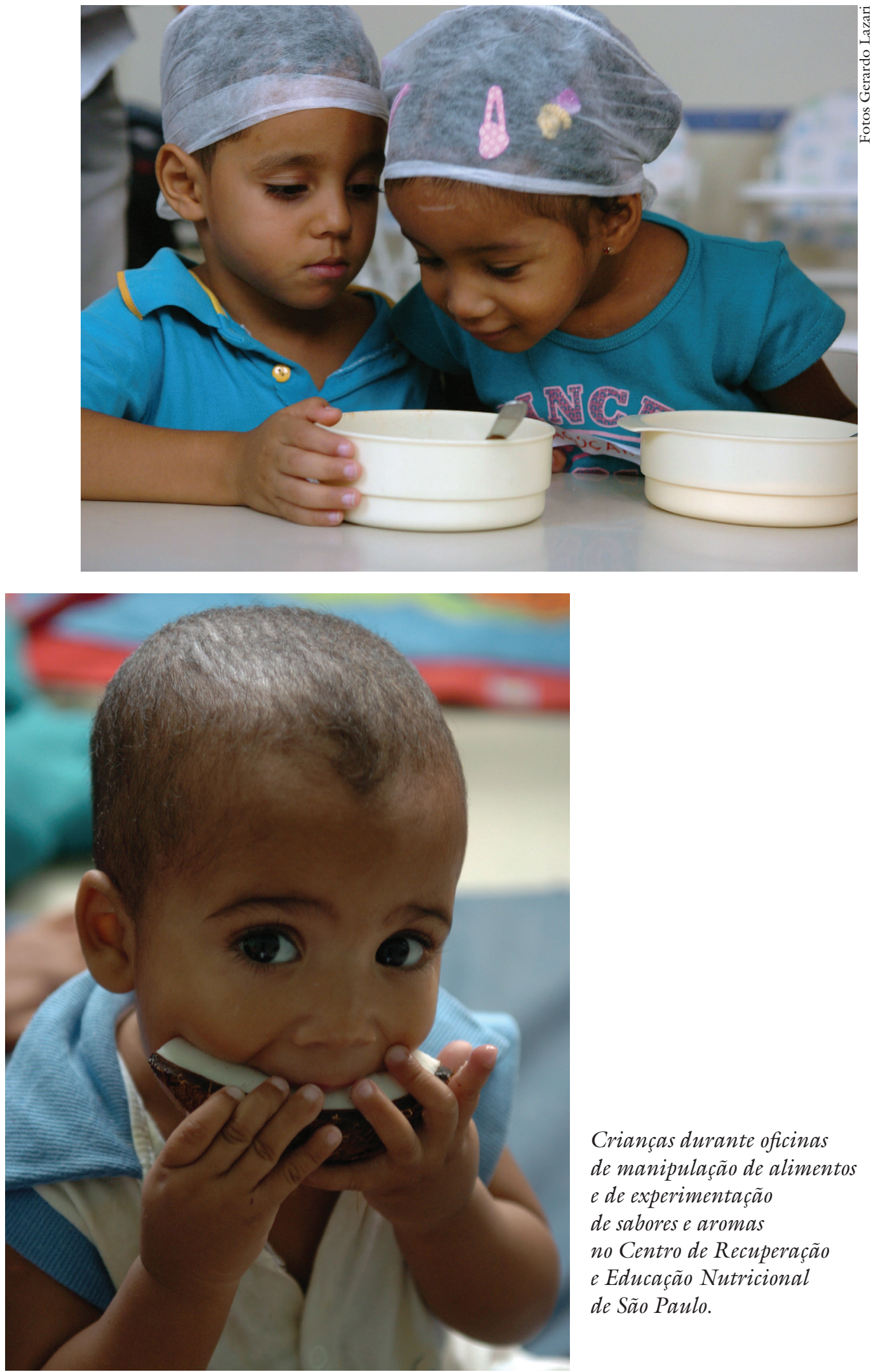

Crianças durante oficinas de manipulação de alimentos $e$ de experimentação de sabores e aromas no Centro de Recuperação e Educação Nutricional de São Paulo. 
tabilização do humor). A irritabilidade e profundo desinteresse e desmotivação por outros objetos ou situações naturalmente recompensadores que caracterizam o estado de abstinência, resultam não só da perda de função do sistema hedônico, mas também da ativação do sistema regulador do estresse da amigdala (ibidem) e de um desbalanço na atividade hormonal. O consumo de cocaína e anfetaminas hiperestimula o circuito neural dopaminérgico, enquanto o consumo de álcool, nicotina e drogas à base de ópio exerce seus efeitos recompensadores através da ativação dos hormônios opioides. A dopamina parece ser o principal mediador da dependência química.

Esses mesmos circuitos são ativados pela ingestão de alimentos altamente palatáveis. Ratos alimentados com açúcar ou mistura de açúcar e gordura desenvolvem compulsão alimentar periódica, tolerância (a quantidade ingerida aumenta com o tempo), demonstram aumento do consumo após um período de abstinência (o que mostra sintomas de privação); e exibem sinais de abstinência semelhantes aos das drogas (bater de dentes, tremor nas patas dianteiras, e sacudir a cabeça) quando a droga naloxone, inibidora do efeito dos hormônios opioides, é administrada em altas doses. Ratos que se tornaram obesos pela ingestão de dietas conhecidas pelo nome de "cafeteria", ricas em açúcar, sal e gordura, apresentam diminuição da atividade dopaminérgica no sistema límbico em relação a ratos com peso normal alimentados com ração. Esses achados demonstram que esses animais tendem a ingerir em maior quantidade alimentos palatáveis para que os níveis de dopamina atinjam o nível normal, semelhante ao efeito descrito para dependentes de drogas. Ainda, estudos com imagens funcionais do cérebro em seres humanos demonstraram que sinais visuais que lembram alimentos e drogas estimulam as mesmas regiões; e que indivíduos obesos e dependentes de drogas mostram respostas cerebrais semelhantes na diminuição dos receptores celulares de captação da dopamina (indicativo de baixa atividade hormonal).

Sinteticamente, há uma base cientifica sólida para a afirmação que seres humanos que apresentam avidez por ingestão de açúcares e alimentos processados possuem alterações nos centros nervosos e neurotransmissores semelhantes às descritas em dependentes químicos (Avena et al., 2008). Estratégias que visem drasticas reduções de peso, dietas restritivas ou mesmo cirurgias bariátricas que não levem em consideração a presença possível de vício alimentar e incluam o tratamento deste distúrbio, terão pouca ou nenhuma chance de sucesso em longo prazo.

Essas considerações apontam para a necessidade de legislação mais aprimorada para regulamentar a produção de alimentos e bebidas industrializados pelo Estado, na mesma direção do que ocorre para o cigarro e drogas; como está ocorrendo nos Estados Unidos (Zhen et al., 2011) e em vários países europeus (Lopes, 2010). 


\section{Modelo Transteórico: uma ferramenta para mudança no comportamento alimentar}

O tratamento de vícios em geral vem sendo exaustivamente estudado há anos com formas e métodos diferentes (fármacos, comportamento, privação) a serem aplicados para atingir o objetivo comum a todos: o cessar de um hábito nocivo. Nessa busca pesquisadores começaram a estudar o comportamento de tabagistas, a fim de entender o motivo pelo qual alguns indivíduos conseguiam simplesmente parar de fumar, outros paravam por um tempo e retornavam e outros não optavam por cessar ou não consideravam um vício (DiClemente; Prochaska, 1982). A partir desse estudo desenvolveu-se uma ferramenta de diagnóstico para identificação do desejo de mudança de um indivíduo com relação a um determinado vício, conhecido como Modelo Transteórico (Toral et al., 2009; Yoshida, 2002; Prochaska et al., 1992). Esse se refere à prontidão para mudança de um determinado comportamento, tendo sido identificados cinco estágios: pré-contemplação, contemplaçãa, preparaçãa, ação e manutenção.

O estágio de pré-contemplação tem como característica principal a falta de vontade para a mudança. A pessoa não pretende mudar agora e nem em um futuro próximo (durante os próximos seis meses). A maioria dos indivíduos nessa categoria, não tem consciência do problema ou até tem conhecimento, mas não faz questão de mudar. São indivíduos que procuram ajuda por influência ou pressão dos familiares, amigos, companheiros, mas não por vontade própria. Exemplo típico: - "Não seria bom você fazer um regime?". E o indivíduo responde: - "Pra quê? Eu me sinto bem assim como estou" (Yoshida, 2002). É, portanto, um estágio caracterizado pela resistência de reconhecer o problema e modificá-lo (Prochaska et al., 1992).

O indivíduo que está no estágio de contemplação tem consciência do seu problema e já vem pensando seriamente em mudar, mas ainda não tomou nenhuma iniciativa ou não sabe por onde começar. Estudos mostram que um indivíduo pode ficar nesse estágio durante anos.

No estágio de preparação há vontade de mudar o comportamento num futuro próximo bem definido. $\mathrm{O}$ indivíduo afirma estar motivado e vislumbra que a mudança poderá ocorrer já nos meses seguintes (ibidem). Esses indivíduos geralmente tentaram no passado, mas não obtiveram sucesso. Nesse grupo, o indivíduo tenta uma série de pequenas mudanças que nem sempre são bem-sucedidas. Um exemplo é a presença declarada e consciente do desejo de começar a dieta e a decisão de iniciá-la em várias segundas-feiras, mas logo abandoná-la no meio da semana, apresentando sempre algumas desculpas.

O estágio de ação está relacionado a ter ocorrido uma mudança efetiva de comportamento e/ou ambiente. O indivíduo realizou experiências reais para cessar o problema, superando assim as barreiras antes percebidas. Essas modificações são visíveis e ocorreram recentemente em menos de seis meses. É um estágio que exige esforço e dedicação para evitar recaídas. Um exemplo é o in- 
divíduo que fez mudanças no consumo alimentar visando o emagrecimento e já consegue reparar os ganhos decorrentes.

Quando o indivíduo já mudou o seu comportamento por um período superior a seis meses, considera-se que está no estágio de manutenção e agora a abordagem é manter aquele hábito alimentar adquirido para que não haja recaídas e o indivíduo não volte a ganhar peso.

Esses estágios de comportamento não são estáticos, podendo-se evoluir, regredir ou estacionar (Toral et al., 2009; Prochaska et al., 1992; De Graaf et al., 1997; Horwath et al., 2013; Szupszynski; Oliveira, 2008; Andretta; Oliveira, 2008; Petroski et al., 2009; Glufke; Nakata, 2011). Por isso é necessário que os profissionais da saúde estabeleçam estratégias de intervenção para incentivar e motivar os indivíduos em tratamento a partir do conhecimento detalhado do estágio em que o indivíduo se encontra (Horwath et al., 2013).

O Modelo Transteórico tem sido utilizado em diferentes áreas de intervenção, tais como, na terapia da dependência química (Szupszynski; Oliveira, 2008), no tratamento de jovens infratores (Andretta; Oliveira, 2008), como motivação para a prática de atividade física (Petroski et al., 2009) e motivação de executivos (Glufke; Nakata, 2011). Mais recentemente vem crescendo sua utilização para avaliação e tratamento da obesidade, assim como para melhoria dos hábitos alimentares (Cattai et al., 2010). Vários estudos mostraram sucesso para introdução de hábitos alimentares saudáveis como consumo de frutas e hortaliças e mudança no consumo de óleos e açúcares quando o processo de educação nutricional foi realizado conforme o estágio de mudança em que o indivíduo se encontrava.

Em conclusão, o crescimento da obesidade no mundo requer múltiplas intervenções por parte do Estado, das indústrias e comércio de alimentos visando à produção de alimentos saudáveis, o controle das propagandas nocivas à saúde e a educação nutricional da população como um todo. Serão necessários muitos esforços para que a alimentação seja uma experiência que realmente contribua para a nossa felicidade.

\section{Referências}

ANDRETTA, I.; OLIVEIRA, M. S. Efeitos da entrevista motivacional em adolescentes infratores. Estudos de Psicologia, 2008.

AVENA, N. M. et al. Evidence for sugar addiction: behavioral and neurochemical effects of intermittent, excessive sugar intake. Neurosci Biobehav. Rev., v.32, n.1, p.20-39, 2008.

BARQUERA, S. et al. Caloric beverage consumption patterns in Mexican children. Nutr J., v.9, p.47, 2010.

BERRIDGE, K. C. The debate over dopamine's role in reward: the case for incentive salience. Psychopharmacology, v.191, n.3, p.391-431, 2007. 
BLUMENTHAL, D. M.; GOLD, M. S. Neurobiology of food addiction. Curr. Opin. Clin. Nutr. Metab. Care, v.13, n.4, p.359-65, 2010.

BOULOS, R. et al. ObesiTV: how television is influencing the obesity epidemic. Physiol. Behav., v.107, n.1, p.146-53, 2012.

BRASIL. Guia alimentar para a população brasileira. Brasil: Ministério da Saúde, 2006. BROWN, C. M. et al. Sugary drinks in the pathogenesis of obesity and cardiovascular diseases. Int. J. Obes., London, v.32, Suppl 6, p.S28-34, 2008.

CATTAI, G. B. P. et al. Internal validation of the stage of change questionnaire for alimentary and physical activity behaviors. Rev. Paul. Pediatr., v.28, n.2, p.194-9, 2010.

COCORES, J. A.; GOLD, M. S. The Salted Food Addiction Hypothesis may explain overeating and the obesity epidemic. Med. Hypotheses, v.73, n.6, p.892-9, 2009.

COLUCCI, A. C. et al. Factors associated with added sugars intake among adolescents living in São Paulo, Brazil. J. Am. Coll. Nutr., v.31, n.4, p.259-67, 2012.

DE GRAAF, C. et al. Stages of dietary change among nationally-representative samples of adults in the European Union. Eur. J. Clin. Nutr., v. 51, Suppl 2, p.S47-56, 1997.

DiCLEMENTE, C. C.; PROCHASKA, J. O. Self-change and therapy change of smoking behavior: a comparison of processes of change in cessation and maintenance. Addict Behav., v.7, n.2, p.133-42, 1982.

FEFERBAUM, R. de. Fluid intake patterns: an epidemiological study among children and adolescents in Brazil. BMC Public Health, v.12, p.1005, 2012.

FERRETTI, S. et al. Developmental overfeeding alters hypothalamic neuropeptide mRNA levels and response to a high-fat diet in adult mice. Peptides, v.32, n.7, p.1371$83,2011$.

GLUFKE, G.; NAKATA, L. E. Modelo Transteórico de mudança: contribuições para o coaching de executivos. Rev. Bras. Orientac. Prof., v.11, n.1, p.61-72, 2011.

HORWATH, C. C. et al. Does the transtheoretical model of behavior change provide a useful basis for interventions to promote fruit and vegetable Consumption? Am. J. Health Promot., 2013.

IBGE. Pesquisa de Orçamentos familiares 2008-2009. In: Estatística IBdGe, editor. Brasil. Disponível em: <http://ibge.gov.br/home/estatistica/populacao/condicaodevida/pof/2008_2009_encaa/pof_20082009_encaa.pdf>. Acesso em: 2010.

JOHNSON, L. et al. Is sugar-sweetened beverage consumption associated with increased fatness in children? Nutrition, v.23, n.7-8, p.557-63, 2007.

KARPPANEN, H.; MERVAALA, E. Sodium intake and hypertension. Prog.Cardiovasc. Dis., v.49, n.2, p.59-75, 2006.

KENNY, P. J. Reward mechanisms in obesity: new insights and future directions. Neuron., v.69, n.4, p.664-79, 2011.

KESSLER, D. A. The end of overeating: controlling the insatiable American appetite. S. 1.: Rodale, 2009. 329p.

KRINGELBACH, M. L.; BERRIDGE, K. C. Towards a functional neuroanatomy of pleasure and happiness. Trends. Cogn. Sci., v.13, n.11, p.479-87, 2009. 
KRINGELBACH, M. L.; ROLLS, E. T. The functional neuroanatomy of the human orbitofrontal cortex: evidence from neuroimaging and neuropsychology. Prog Neurobiol., v.72, n.5, p.341-72, 2004.

LOPES, C. A. Legislação de proteção de crianças e adolescentes contra publicidade ofensiva: a situação do Brasil e o panorama internacional. Brasília: Biblioteca Digital Câmara dos Deputados, 2010.

MALIK, V. S. et al. Sugar-sweetened beverages and risk of metabolic syndrome and type 2 diabetes: a meta-analysis. Diabetes Care., v.33, n.11, p.2477-83, 2010.

MANABE, Y. et al. Preference for High-Fat Food in Animals. In: MONTMAYEUR, J. P.; LE COUTRE, J. (Ed.) Fat detection: taste, texture, and post ingestive effects. Boca Raton: CRC Press, 2010.

McCRORY, M. A. et al. Dietary variety within food groups: association with energy intake and body fatness in men and women. Am. J. Clin. Nutr., v.69, n.3, p.440-7, 1999.

NORGREN, R. et al. Gustatory reward and the nucleus acumbens. Physiol. Behav., v.89, n.4, p.531-5, 2006.

PETROSKI, E. L. et al. Estágios de mudança de comportamento e percepção positiva do ambiente para atividade física em usuários de parque urbano. S. 1.: Fundação Técnica e Científica do Desporto, 2009.

PROCHASKA, J. O. et al. In search of how people change. Applications to addictive behaviors. Am. Psychol., v.47, n.9, p.1102-14, 1992.

RADA, P. et al. Daily bingeing on sugar repeatedly releases dopamine in the acumbens shell. Neuroscience, v.134, n.3, p.737-44, 2005.

REALE, G. Aristóteles. São Paulo: Loyola, 2007.

Sofistas, Sócrates e socráticos menores. São Paulo: Loyola, 2009. 248p.

SAWAYA, A. L. Alimentos industrializados/comercializados e o desbalanço fisiológico: memória, aprendizagem e contexto social. In: SAWAYA, A. L. et al. (Ed.) Fisiologia da nutrição na saúde e na doença. Da biologia molecular ao tratamento. São Paulo: Atheneu; 2013a.

Alimentos ricos em açúcar, gordura e sal induzem à hiperfagia e ao vício alimentar. In: SAWAYA, A. L. et al. (Ed.) Fisiologia da nutrição na saúde e na doença. Da biologia molecular ao tratamento. São Paulo: Atheneu; 2013b.

SPANGLER, R. et al. Opiate-like effects of sugar on gene expression in reward areas of the rat brain. Brain. Res. Mol. Brain Res., v.124, n.2, p.134-42, 2004.

SZUPSZYNSKI, K.; OLIVEIRA, M. S. O Modelo Transteórico no tratamento da dependência química. Psicol. Teor. Prat., v.10, p.162-73, 2008.

TEY, S. L. et al. Long-term consumption of high energy-dense snack foods on sensory-specific satiety and intake. Am. J. Clin. Nutr., v.95, n.5, p.1038-47, 2012.

TORAL, N. et al. Healthy eating according to teenagers: perceptions, barriers, and expected characteristics of teaching materials. Cad Saude Publica, v.25, n.11, p.2386-94, 2009.

WHO. Diet, nutrition and the prevention of chronic dieases. Geneva: WHO, 2003.

XUE, Y. X. et al. A memory retrieval-extinction procedure to prevent drug craving and relapse. Science, v.336, n.6078, p.241-5, 2012. 
YEOMANS, M. R. Taste, palatability and the control of appetite. Proc. Nutr. Soc., v.57, n.4, p.609-15, 1998.

YOSHIDA, P. M. E. Stages of change scales: clinical and research application. Psico-USF, 2002.

ZHEN, C. et al. Habit formation and demand for sugar-sweetened beverages. Am. J. Agr. Econ., v.93, n.1, p.175-93, 2011.

ZHENG, H. et al. Appetite control and energy balance regulation in the modern world: reward-driven brain overrides repletion signals. Int. J. Obes, London, v.33, Suppl. 2, p.S8-13, 2009.

RESUMO - Quase dois bilhões de pessoas tem excesso de peso. Esse distúrbio alimentar vem acometendo cada vez mais crianças/adolescentes. Embora seja uma doença multicausal, há forte evidência da influência da propaganda e do ambiente obesogênico na mudança dos hábitos alimentares. As indústrias/comércio de alimentos desenvolveram técnicas capazes de gerar consumo excessivo através do desenvolvimento de sabores, imagens e técnicas de persuasão, e da produção de alimentos ricos em açúcar, sal e gordura que são nutrientes recompensadores e podem gerar vício alimentar. Este artigo debruça-se sobre a influência do consumo de alimentos palatáveis na neuroanatomia funcional do prazer e sua implicação para o vício alimentar. Discute ainda o Modelo Transteórico como ferramenta para intervenção no tratamento da obesidade.

PALAVRAS-CHAVE: Vício alimentar, Açúcar, Gordura, Sal, Felicidade.

ABSTRACT - Nearly two billion people are overweight. This eating disorder is affecting more and more children/teenagers. Although it is a multifactorial disease, there is strong evidence of the influence of advertising and the obesogenic environment in changing dietary habits. Industry/commerce food techniques can generate excessive consumption by developing flavors, images and techniques of persuasion, and by the production of foods high in sugar, salt and fat which are rewarding nutrients. This article focuses on the influence of the consumption of palatable food in the functional neuroanatomy of pleasure and its implication for food addiction. It also discusses the transtheoretical model as a tool for intervention in the treatment of obesity.

KEYWORDS: Food addiction, Sugar, Fat, Salt, Happiness.

Ana Lydia Sawaya é professora associada do Departamento de Fisiologia, Disciplina de Fisiologia da Nutrição da Universidade Federal de São Paulo. É coordenadora do Grupo de Pesquisa em Nutrição e Pobreza do Instituto de Estudos Avançados da USP, diretora científica do Instituto Salus e Centro de Recuperação e Educação Nutricional. @- alsawaya@unifesp.br

Andrea Filgueiras é nutricionista, mestranda do Programa de Pós-Graduação em Pediatria da Universidade Federal de São Paulo. @ - andrea.filgueiras@gmail.com

Recebido em 23.5.2013 e aceito em 15.6.2013. 